\title{
Calendar Effects In The Indian Stock Market
}

Jayen B. Patel, (Email: jpatel@adelphi.edu), Adelphi University

\begin{abstract}
We find two distinct calendar effects in returns for the Indian stock market. More specifically, we find a November-December effect in which we document that mean returns for November and December are significantly greater than those of the other ten months. We also identify a Marchto-May effect in which mean returns for the months March to May are significantly less than those during the other nine months. We further demonstrate that these are two distinct effects that are independent of each other.
\end{abstract}

Keywords: Indian stock market, calendar effects, efficient market hypothesis, emerging markets.

\section{INTRODUCTION}

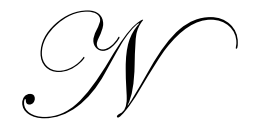

umerous researchers have challenged the efficient market hypothesis (EMH) in the U.S. securities markets as well as in many international securities markets. The EMH is based on the premise that security returns follow a random walk and, therefore, calendar return regularities are inconsistent with the notion of efficient capital markets. The two most closely examined calendar effect regularities are, arguably, the day-of-the-week effect and the January effect. Security returns exhibit the day-of-the-week effect when returns for each trading day of the week are not statistically equal. The existence of a January effect means that returns for the month of January are statistically significantly greater than those during the remaining months of the year. Recent literature suggests that, in recent years, these two effects have become less prominent and may, in fact, be disappearing. However, detection of a host of other calendar regularities continues to proliferate in global securities markets.

Critics argue that detection of calendar regularities does not necessarily translate in to economic advantages for investors. Excessive trading may result in significantly increased transaction costs and, therefore, investment strategies dependent on these calendar effects may not be economically advantageous. Furthermore, most studies examining calendar anomalies use essentially the same data from securities markets in developed nations. Excessive examination of the same data creates a "data mining" problem.

A number of researchers have examined emerging stock markets for the existence of calendar effect regularities. Emerging stock markets are viewed as fundamentally different from the markets of developed nations, and data from emerging stock markets are examined relatively less frequently than those of developed stock markets. However, conclusions drawn from a few studies of calendar effects in emerging markets may not necessarily be adequate and complete as these economies are, by definition, in transition as they continuously develop. Since we do not always have reliable long-term time series data, incorporation of additional data may reinforce or, perhaps, invalidate previous conclusions. In the spirit of this reasoning, we reexamine the existence of the calendar effects in the Indian stock market.

Patel (2003) examined the relationship between the U.S. stock market and ten emerging stock markets of Asia. He found that the Indian stock market and other South Asian markets were distinct from other emerging stock markets of Asia. In a later study, Patel (2006) focused exclusively on the Indian and the U.S. stock markets. He utilized three Indian stock indexes, namely, the BSE 30, BSE 100 and BSE 200 stock indexes, while the DJIA, S\&P 500 and NASDAQ were utilized as representative U.S. stock indexes. He found that the Indian stock market has 
offered important return and diversification benefits to U.S. investors, particularly during those periods when the U.S. market generated relatively lower returns.

The paper is organized as follows. The next section discusses some of the published literature relevant to our study. The following section describes the data. We then discuss our empirical results, and plausible explanations of our findings and the last section summarizes the major findings of our paper.

\section{LITERATURE REVIEW}

Published studies that have examined calendar effects in the Indian stock market appear to be limited. Kaur (2004) reports that few studies have examined the day-of-the-week effect in the Indian stock market, and further notes the absence of studies that examine monthly seasonality in the Indian stock market. Kaur utilized two Indian stock indexes, the Bombay Stock Exchange (BSE) 30 index and the National Stock Exchange (NSE) S\&P CNX Nifty stock index, to examine the day-of-the-week effect and the monthly effect. Kaur did not find a January effect in the Indian stock market, but did find that March and September generated substantially lower returns, whereas February and December generated substantial positive returns.

Sarma (2004) adds that very few studies have examined calendar effects during the post reform era in the Indian stock market. Sarma investigated the BSE 30, the BSE 100, and the BSE 200 stock indexes to detect the dayof-the-week effect. Utilizing Kruskal-Wallis test statistics, Sarma concluded that the Indian stock market exhibited some seasonality in daily returns over the period January 1, 1996 to August 10, 2002. Bodla and Jindal (2006) examined several seasonal anomalies in the Indian stock market utilizing the S\&P CNX Nifty Index for the period January 1998 to August 2005. For the monthly effect, they did find some significant differences utilizing ANOVA for their sub-period, January 2002 to August 2005. However, they were unable to find any significant differences among individual months. In an earlier study, Ignatius (1998) examined seasonality in a BSE index and in the Standard and Poor's 500 stock index for the period 1979-1990. Ignatius found that December generated the highest mean returns, and that April and June generated high returns in the Indian stock index.

Some studies examine seasonality in the Indian stock market as part of a broader analysis of seasonality in several major emerging stock markets. For example, Fountas and Segredakis (2002) investigate monthly seasonal anomalies in eighteen major emerging equity markets, including the Indian stock market. They examined the monthly effect for the period January 1987 to December 1995. For the Indian stock market, they found August returns were significantly greater than April, May, October and November returns. However, they did not find evidence consistent with hypothesized tax-loss selling in the Indian stock market, as the tax-year in India commences in April.

Yakob, Beal and Delpachitra (2005) examined seasonal effects in ten Asian Pacific stock markets, including the Indian stock market, for the period January 2000 to March 2005. They state that this is a period of stability and is therefore ideal for examining seasonality as it was not influenced by the Asian financial crisis of the late nineties. Yakob, et al., concluded that the Indian stock market exhibited a month-of-the-year effect in that statistically significant negative returns were found in March and April whereas statistically significant positive returns were found in May, November and December. Of these five statistically significant monthly returns, November generated the highest positive returns whereas April generated the lowest negative returns.

Evidence of monthly seasonality in the Indian stock market is somewhat mixed. This may be, in part, a consequence of the fact that the Indian economy is in transition and is therefore constantly evolving, supporting the notion that further research into these calendar effects in the Indian stock market is warranted. We are more interested in finding broader patterns of seasonality that would be economically advantageous to investors. Next, we summarize some studies that have documented broader seasonal patterns in the markets.

Patel and Evans (2003) investigated seasonal patterns in the stock markets of the seven most industrialized (G7) nations. They examined seasonality for the period from January 1960 to December 2001, and found that, in all G7 countries, mean stock returns for December through May were significantly greater than mean returns for June 
to November. They further demonstrated that this pattern was not related to the January effect, and, unlike the January effect, this pattern has become more prevalent in later years of their study.

Keppler and Xue (2003) document seasonal price behavior for eighteen equity markets in developed countries over the period 1970 to 2001 . The authors found that these markets generated substantially higher returns from November through April than over the months May through October. Keppler and Xue refer to the NovemberApril sub-period as "Good Months" and the period May-October as "Bad Months" for stock market investing.

Lucy and Whelan (2004) examined monthly and semi-annual behavior of the Irish stock market. In their investigation of half-year seasonality, they found returns from November to April were greater than returns for the six months May through October. This half-year effect was somewhat consistent for different sub-samples of their study.

\section{INDIAN STOCK MARKET DATA}

The two largest stock exchanges in India are the Bombay Stock Exchange and the National Stock Exchange of India. The Indian economy has grown rapidly in the last ten to fifteen years, and both of these exchanges have continued to reactively construct new stock market indexes in order to more accurately represent the overall Indian market.

The Bombay Stock Exchange (BSE) created the BSE 500 stock market index on February 1, 1999. This index of 500 stocks is designed to better portray the changing nature of the Indian economy, and represents nearly 93 percent of the market capitalization of the BSE (BSE website, June 2006). Consequently, the BSE 500 is generally considered representative of the Indian stock market.

India Index Services and Products Limited (IISL) was created in 1998 to provide a variety of stock market indexes to the National Stock Exchange of India (NSE). IISL has a consulting and licensing agreement with Standard and Poor's (NSE website, June 2006). The NSE S\&P CNX 500 (NSE 500), a broad-based index of 500 stocks, was created on June 7, 1999. According to the NSE, this index represents approximately 93 percent of the exchange's market capitalization and approximately 87 percent of NSE turnover, and is therefore representative of the overall Indian stock market.

We collected values for each index for the last trading day of each month. Data for last trading day of the month for each index were available from June 1999 to June 2007, so that we have ninety-six monthly return observations, i.e. from July 1999 to June 2007 for each index. Since each index represents over ninety percent of the market capitalization of its respective exchange and each index is representative of the overall Indian stock market, we expect similar results for our analysis of each of the two data sets over the sample period. Results are reported in the next section.

\section{EMPIRICAL RESULTS}

We initially present mean returns by calendar month for each of the two Indian indexes. We find that the highest mean returns for each index were generated during the month of November. December and August also generated relatively high returns. The month of March generated negative mean returns, the lowest for each index, and April and May also generated substantially lower returns for each index.

In this study, we seek to identify a series of consecutive months during which the Indian stock market generates extraordinarily high (or low) returns. Identification of such a pattern may enable investors to enhance investment returns. More specifically, an investor should be invested during the consecutive months when the Indian stock market generates high positive returns, and, alternately, an investor should invest out of the Indian stock market in consecutive months when stocks generate substantially negative returns. 
Table 1

Mean Monthly Percentage Returns for Two Indian Stock Indexes

\begin{tabular}{cccc}
\hline & July 1999 to June 2007 & Observations \\
\hline Month & BSE 500 & NSE 500 & 8 \\
January & 2.13 & 2.13 & 8 \\
February & 2.12 & 1.95 & 8 \\
March & -3.80 & -3.74 & 8 \\
April & -0.71 & -1.26 & 8 \\
May & -1.05 & -1.28 & 8 \\
June & 2.78 & 2.83 & 8 \\
July & 1.00 & 1.09 & 8 \\
August & 6.79 & 6.69 & 8 \\
September & -0.31 & -0.51 & 8 \\
October & -0.18 & -0.33 & 8 \\
November & 8.55 & 8.46 & 96 \\
December & 6.40 & 6.79 & 1.90 \\
Overall & 1.98 & & 8 \\
\hline
\end{tabular}

We observe two distinct return patterns in the Indian stock market. We first present results for the BSE 500 index. November $(8.55 \%)$ and December $(6.40 \%)$ generated substantially greater returns than those for almost all other months. High positive returns were also generated during August, but the months of September and October have negative returns. We believe that investors should minimize trading in order to earn high returns by avoiding excessive transaction related costs. We therefore conclude that an investor should have been invested in the Indian stock market during the months of November and December (Nov-Dec). A similar pattern is presented for the second index, the NSE 500. Greater mean returns are generated during November (8.46\%) and December (6.79\%) than during the other ten months of the year, so that again we find that an investor would have earned high returns by being invested in the Indian stock market during Nov-Dec.

We also identify three consecutive months during which the Indian stock market generates substantial negative returns. For each index, the months March through May produce negative returns substantially lower than the returns for the other nine months. For the BSE 500, the lowest mean returns were produced during March ($3.80 \%)$, followed by May (-1.05\%) and April (-0.71\%), respectively. Similarly, for the NSE 500, the lowest mean returns are observed for March (-3.74\%), followed by May (-1.28\%) and April (-1.26\%), respectively. During the period of our study, investors should have been invested out of the Indian stock market during the months March through May (Mar-to-May).

Table 2

Mean Monthly Returns for Nov-Dec Versus Remaining Ten Months July 1999 to June 2007

\begin{tabular}{cccc}
\hline Mean Monthly Returns: & BSE 500 & NSE 500 & Observations \\
\hline Nov-Dec & 7.48 & 7.62 & 16 \\
Remaining Ten Months & 0.88 & 0.76 & \\
T-Test Statistics: & & & \\
T-Value & 3.19 & 3.30 \\
Significance & 0.002 & 0.001 & \\
$\quad$ & & & \\
Mann-Whitney Test Statistics: & -3.20 & \\
$\quad$ Z-Value & -3.17 & 0.001 & \\
Significance & 0.002 &
\end{tabular}

Note: Nov-Dec represents mean monthly returns of November and December.

Remaining Ten Months represents mean monthly returns from January to October. 
In Table 2, we separate the Nov-Dec months from the remaining ten months of the year. For each index, average monthly returns for these two months are substantially greater than the average for the remaining ten months. For the BSE 500, the average return for Nov-Dec is $7.48 \%$, compared to an average of a mere $0.88 \%$ for the remaining ten months. Results of parametric T-tests, as well as non-parametric Mann-Whitney tests, confirm that mean returns for the Nov-Dec months are statistically significantly greater than the mean returns for the remaining ten months of the year for the period of our study.

Similarly, for the NSE 500, Nov-Dec produced average returns of $7.62 \%$, compared to a $0.76 \%$ average for the other ten months. Both T-tests and Mann-Whitney tests confirm that the Nov-Dec months generate statistically significantly greater mean returns than the mean returns for the remaining ten months.

Our objective in this study is to first, identify consecutive months that generate high positive returns in the Indian stock market, and, second, identify consecutive months that generate negative returns. We now compare mean returns for March to May (Mar-to-May) with those for the remaining nine months. The results of this comparison are presented in Table 3.

For the overall sample period July 1999 to June 2007, mean returns for the BSE 500 index for Mar-to-May $(-1.85 \%)$ are substantially less than those for the remaining nine months $(3.25 \%)$. Results are virtually identical for the NSE 500 index: Mar-to-May mean returns $(-2.09 \%)$ are negative and substantially less than the mean for the remaining nine months $(3.23 \%)$. Both T-tests and Mann-Whitney tests indicate that these differences are statistically significant, confirming that, for each index, Mar-to-May returns are significantly less than those for the remaining months. Investors would therefore have benefited by avoiding investing in the Indian stock market during the months March through May.

Table 3

Mean Monthly Returns for Mar-to-May Versus Remaining Nine Months July 1999 to June 2007

\begin{tabular}{cccc}
\hline Mean Monthly Returns: & BSE 500 & NSE 500 & Observations \\
\hline Mar-to-May & -1.85 & -2.09 & 24 \\
Remaining Nine Months & 3.25 & 3.23 & \\
T-Test Statistics: & & & -2.94 \\
$\quad$ T-Value & -2.84 & 0.004 & \\
Significance & 0.006 & & \\
$\quad$ & & -2.44 & \\
Mann-Whitney Test Statistics: & & 0.015 \\
$\quad$ Z-Value & -2.33 & 0.020 & \\
Significance &
\end{tabular}

Note: Mar-to-May represents mean monthly returns for March to May.

Remaining Nine Months represents mean monthly returns for January, February, and June to December.

We next analyze the two effects, namely, the Nov-Dec effect and the Mar-to-May effect, in greater detail, in order to determine whether these effects are inter-related. We report that mean returns for Nov-Dec are greater than the mean for the remaining months of the year. However, it is possible that the Mar-to-May months influence mean returns for the remaining ten months. We therefore exclude Mar-to-May from the remaining ten months in order to determine whether the Nov-Dec months indeed generate substantially higher mean returns when compared to returns for the remaining seven months.

Additionally, we can make a similar argument for the Mar-to-May effect; that is, it is possible that mean returns for Mar-to-May are lower than those for the remaining nine months because of the Nov-Dec effect. We therefore separate the Mar-to-May and Nov-Dec effects from the remaining seven months of the year. The results are displayed in Table 4. 
Mean returns for Mar-to-May, Nov-Dec and the remaining seven months are presented in Table 4. For the BSE 500, Nov-Dec has the highest mean return (7.48\%), while the months Mar-to-May generated the lowest mean return $(-1.85 \%)$ among the three groups. Similarly, for the NSE 500, mean returns for Nov-Dec $(7.62 \%)$ are highest, while mean returns for Mar-to-May are lowest $(-2.09 \%)$. For each index, the remaining seven months' returns are lower than the Nov-Dec returns and higher than the Mar-to-May returns, so that mean returns for Nov-Dec continue to be greater than those of the remaining months even after excluding Mar-to-May. Similarly, mean returns for Mar-to-May are lower than those for the remaining seven months after excluding the months Nov-Dec.

Table 4

Mean Returns and Significance Tests of Three Groups July 1999 to June 2007

\begin{tabular}{|c|c|c|c|}
\hline Mean Monthly Returns: & BSE 500 & NSE 500 & Observations \\
\hline Nov-Dec & 7.48 & 7.62 & 16 \\
\hline Remaining Seven Months & 2.05 & 1.98 & 56 \\
\hline Mar-to-May & -1.85 & -2.09 & 24 \\
\hline $\begin{array}{c}\text { ANOVA Test Results: } \\
\text { F-Value } \\
P \text {-value }\end{array}$ & $\begin{array}{c}7.62 \\
0.001\end{array}$ & $\begin{array}{c}8.17 \\
0.001\end{array}$ & \\
\hline $\begin{array}{c}\text { Kruskal-Wallis Test Results } \\
\text { Chi-Square } \\
P \text {-value }\end{array}$ & $\begin{array}{l}12.46 \\
0.002\end{array}$ & $\begin{array}{l}12.99 \\
0.002\end{array}$ & \\
\hline
\end{tabular}

Note: Nov-Dec represents mean monthly returns of November and December.

Mar-to-May represents mean monthly returns from March to May.

Remaining Seven Months represents mean monthly returns for January, February, and June to October.

We test the differences among the three groups, namely, Nov-Dec, Mar-to-May and the remaining seven months, using ANOVA as well as Kruskal-Wallis tests. The null and alternate hypotheses are as follows:

$\mathbf{H}_{0}$ : $\quad$ Group $1($ Nov-Dec) $=$ Group 2 (Remaining Seven Months $)=$ Group 3 (Mar-to-May)

$\mathbf{H}_{1}$ : At least one group mean is different from another group mean.

The ANOVA and Kruskal-Wallis tests do not identify specific significant comparisons. The statistical tests indicate whether at least one group mean is statistically significantly different from the mean for the other group(s). If the F-value (or Chi-square) is significant, then we utilize statistical comparison tests to identify individual significant differences. The results are presented in Tables 4 and 5, respectively.

In Table 4, we report the ANOVA and Kruskal-Wallis test results for each index. We reject the null hypothesis for each index, concluding that the means for the three groups are not equal. Specifically, we conclude that at least one group mean is statistically significantly different from another group mean. We utilize parametric ttests and non-parametric Mann-Whitney tests in order to detect specific differences. Results of these tests are in Table 5 .

For each index, Nov-Dec mean returns were statistically significantly greater than the means for the other two groups, Mar-to-May and the remaining seven months. Also, returns for Mar-to-May were statistically significantly less than the means for the other two groups, Nov-Dec and the remaining seven months. The results of these tests confirm that, in the Indian stock market, the two effects, namely, the Nov-Dec effect and the Mar-to-May effect, are independent. 
Table 5

Significance Tests for Comparisons of the Three Groups July 1999 to June 2007

\begin{tabular}{|c|c|c|c|c|c|}
\hline \multirow[b]{2}{*}{ Group Comparisons } & \multicolumn{2}{|c|}{ T-Statistics } & \multicolumn{3}{|c|}{ Mann-Whitney } \\
\hline & T-Value & Sign. & df & Z-Statistic & Sign. \\
\hline \multicolumn{6}{|l|}{ BSE 500 Index: } \\
\hline Group 1 with Group 2 & 2.96 & 0.004 & 70 & -2.79 & 0.005 \\
\hline Group 1 with Group 3 & 3.50 & 0.001 & 38 & -3.20 & 0.001 \\
\hline Group 2 with Group 3 & 2.06 & 0.043 & 78 & -1.67 & 0.095 \\
\hline \multicolumn{6}{|l|}{ NSE 500 Index: } \\
\hline Group 1 with Group 2 & 3.02 & 0.003 & 70 & -2.79 & 0.005 \\
\hline Group 1 with Group 3 & 3.64 & 0.001 & 38 & -3.29 & 0.001 \\
\hline Group 2 with Group 3 & 2.15 & 0.035 & 78 & -1.77 & 0.076 \\
\hline
\end{tabular}

Note: Group 1 is Nov-Dec; Group 2 is Remaining Seven Months; Group 3 is Mar-to-May

Next we evaluate the consistency and robustness of the pattern identified in the overall sample. We created two four-year sub-periods from our overall sample period of eight years: the first sub-period is from July 1999 to June 2003, and the second sub-period is from July 2003 to June 2007. We investigate whether the Nov-Dec (Marto-May) mean returns are consistently greater (less) than those of the remaining months for the two sub-periods. The results are reported in Table 6.

In each sub-period, mean returns for the months Nov-Dec are greater than those for the other two groups, Mar-to-May and the remaining seven months. Also, for each period, mean returns for Mar-to-May are less than the mean for each of the other two groups. We find a consistent robust return pattern in each Indian stock market index in that, during each period, the highest mean return is produced during the months Nov-Dec, the second highest mean return occurs during the remaining seven months, and the lowest mean return is during the months Mar-toMay.

Table 6

Mean Returns of Three Groups By Two Sub-periods July 1999 to June 2007

\begin{tabular}{cccc}
\hline Mean Monthly Returns: & BSE 500 & NSE 500 & Observations \\
\hline & Sub-period 1: July 1999 to June 2003 & 8 \\
Nov-Dec & 6.44 & 6.77 & 28 \\
Remaining Seven Months & 1.00 & 0.96 & 12 \\
Mar-to-May & -3.91 & -4.32 & 48 \\
Overall & 0.68 & 0.61 & \\
& & & \\
\hline & Sub-period 2: July 2003 to June 2007 & \\
\hline Nov-Dec & 8.51 & 8.48 & 28 \\
Remaining Seven Months & 3.09 & 2.99 & 12 \\
Mar-to-May & 0.21 & 0.13 & 48 \\
Overall & 3.27 & 3.19 & \\
\hline
\end{tabular}

Note: Nov-Dec represents mean monthly returns of November and December.

Mar-to-May represents mean monthly returns from March to May.

Remaining Seven Months represents mean monthly returns for January, February, and June to October.

\section{PLAUSIBLE EXPLANATIONS}

The obvious issue that arises from our results is whether there are plausible explanations for the existence of these distinct patterns of returns. While these are ultimately empirical matters to be addressed in future research, each of the two patterns seems to be associated with important social and economic events on the Indian calendar. It 
is conceivable that the Nov-Dec effect is related to the Hindu festival of Diwali, which is generally celebrated in late October or early November. On the other hand, the Mar-to-May effect may be a consequence of the fact that the Indian national budget is announced during the month of February, and the tax year in India ends in March.

Majority of Indians are Hindus, and celebrate Diwali as the beginning of the New Year. Diwali is celebrated for several days and the precise date of the celebration is determined each year according to the Hindu calendar. During the celebration, Hindus purchase and exchange goods and commodities, and often receive substantial bonuses from their employers. In general, the holiday period generates a substantial economic stimulus for the Indian economy. It seems plausible to speculate that the holiday period also has a substantial positive impact on the Indian stock market, although, as noted above, additional research in to this issue would clearly be required in order to provide a more meaningful conclusion. Additionally, researchers might investigate whether the Nov-Dec calendar regularity is related to the inherent structure and settlement procedures of the Indian stock exchanges.

As noted above, February and March are significant dates related to the Indian national budget and tax year. Kaur's (2004) explanation related to these dates might form the basis for a plausible explanation of our observed Mar-to-May effect. Kaur has stated that, after the budget is presented in February, the Indian stock market goes on a selling spree during subsequent months resulting in increased volatility and decreased returns. These observations are consistent with our conclusions regarding the Mar-to-May effect.

\section{SUMMARY AND CONCLUSIONS}

We have examined two broad-based Indian stock market indexes for the period July 1999 to June 2007, and identified two separate calendar effects. First, we identify a Nov-Dec effect, such that mean returns for the months November and December are significantly greater than mean returns during the remaining ten months of the year. Second, we have identified a Mar-to-May effect, whereby mean returns for March through May are significantly less than those during the remaining months.

The Indian stock market has grown substantially in recent years, and it appears that the Indian economy is still in transition, so that findings from earlier studies may evolve as additional data become available for subsequent years. Calendar effect studies should be reexamined over time, particularly when stock market characteristics change rapidly. For the sample period examined in this study, the Nov-Dec (Mar-to-May) monthly returns generated significantly higher (lower) returns than those for the other months of the year.

The investment community and researchers alike are eager to understand the behavior of the Indian stock market. We believe that our study makes both timely and useful contributions to an understanding of calendar effects in the Indian stock market. We suggest, however, that the results of this study should be considered a preliminary anecdote. We encourage researchers to further examine calendar effects in the Indian stock market and to update the conclusions of our study.

\section{ACKNOWLEDGEMENTS}

I would like to thank Allan Ashley and R. Bruce Swensen for helpful comments and suggestions.

\section{REFERENCES}

1. B. S. Bodla and Kiran Jindal, Seasonal Anomalies in Stock Returns: Evidence from India and the US, Decision, Volume 33, Number 1, January-June 2006.

2. Bombay Stock Exchange Website, www.bseindia.com

3. Stilianos Fountas and Konstantinos N. Segredakis, Emerging stock markets return seasonalities: the January effect and the tax-loss selling hypothesis, Applied Financial Economics, Volume 12, 2002, pp. 291-299.

4. Roger Ignatius, The Bombay Stock Exchange: Seasonalities and Investment Opportunities, Managerial Finance, Volume 24, Number 3, 1998, pp. 52-58. 
5. Harvinder Kaur, Time Varying Volatility in the Indian Stock Market, Vikalpa, Volume 29, Number 4, October-December 2004, pp. 25-42.

6. Michael Keppler and Xing Hong Xue, The Seasonal Price Behavior of Global Equity Markets, The Journal of Investing, Winter 2003, pp. 49-53.

7. National Stock Exchange Website, www.nseindia.com

8. Jayen B. Patel, Diversification in an Emerging Market: A Closer Look at the Indian Stock Market, International Business and Economics Research Journal, Volume 5, Number 1, January 2006, pp. 55-64.

9. Jayen B. Patel, Inter-Temporal Relationship Between the U.S. Stock Market and the Emerging Markets of Asia, Journal of Business and Economics Research, Volume 1, Number 10, October 2003, pp. 1-6.

10. Jayen B. Patel and Dorla A. Evans, Seasonal Stock Return Patterns in the Seven Industrialized Nations, The Journal of Applied Business Research, Volume 19, Number 3, Summer 2003, pp. 111-120.

11. S. N. Sarma, Stock Market Seasonality in an Emerging Market, Vikalpa, Volume 29, Number 3, JulySeptember 2004, pp. 35-41.

12. Brian M. Lucey and Shane Whelan, Monthly and semi-annual seasonality in the Irish equity market 19342000, Applied Financial Economics, Volume 14, 2004, pp. 203-208.

13. Noor Azuddin Yakob, Diana Beal and Sarath Delpachitra, Seasonality in the Asia Pacific Stock Markets, Journal of Asset Management, Volume 6, Number 4, 2005, pp. 298-318.

\section{NOTES}


NOTES 